\title{
Über Medizinethnologie, weibliche Beschneidung und das kulturelle «Verstehen»
}

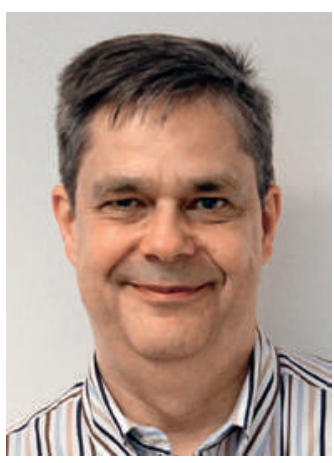

Eberhard Wolff
Wenn ein Buch im Untertitel «Eine Einführung» heisst, erwartet man einen ruhigen Überblick über den Wissens- und Diskussionsstand eines Fachs. Bei der Medizinethnologie ist alles ein wenig anders: kein sehr etabliertes Fach, kein klarer Wissenskanon. Das Einführungsbuch in die Medizinethnologie, um das es hier geht [1], ist jetzt zum vierten Mal mit komplett neu verfasstem Text erschienen.

Eines der Hauptcredos der Medizinethnologie ist «zu zeigen, dass andere Menschen die Welt ganz anders sehen mögen als wir» (so Wolfgang Bichmann im Vorwort). Mit einem Blick auf die Kontexte des jeweiligen Gesundheitsverhaltens können wir andere Kulturen (und natürlich auch uns selbst) besser verstehen.

Dieses Credo versucht die Ethnologin und Herausgeberin des Bandes Katarina Greifeld gerade dort umzusetzen, wo das «Verstehen» für viele von uns wohl am allerschwierigsten ist: beim «Reizthema» der weiblichen Genitalbeschneidung der Klitoris und/oder der kleinen Schamlippen, wie sie besonders im westlichen und nordöstlichen Afrika durchgeführt wird. Mit einigem inneren Schauer läuft einem da im Kopf die Begriffskette ab, die in der öffentlichen Debatte schwebt: Verstümmelung, Gewalt gegen Frauen, Menschenrechtsverletzung, Verletzung von grundlegenden Kinderrechten, der schädliche Einfluss des Islams, der Tradition. In summa: Skandal. Doch, so Greifeld, das Thema der weiblichen Beschneidung sei «seit Jahren mit Emotionen belastet und nur schwer öffentlich zu diskutieren, weil sofort Werte und Wertungen eingeführt werden». Statt dessen solle man mit mehr Sachlichkeit und weniger Emotionalität beginnen. Bereits mit dem anklagenden Begriff der «Verstümmelung» werde «man der Selbstsicht der Frauen nicht gerecht, die eine Beschneidung für sich und ihre Töchter wollen». Für ihre Argumentation greift Greifeld auf eine Studie aus dem westafrikanischen Mali zurück, wo etwa 90\% der Frauen beschnitten sind. In ihr wurden auch die verbreiteten Begründungen für die Beschneidung untersucht.

Aus diesen Ergebnissen schliesst Greifeld in etwa: Ja, es geht dabei um die Kontrolle der weiblichen Sexualität, aber nicht darum, sie zu negieren. Ja, die Beschneidung wird oft islamisch begründet, aber auch ausserhalb des Islams praktiziert. Eine treibende Kraft der weiblichen Beschneidung sei statt Tradition und Religion die soziale Norm, dass nur eine beschnittene Frau eine richtige Frau sei, die nicht untreu würde und die Ehre der Familie nicht verletze. Ja, es geht auch um männliche Machtausübung und um die Macht, wie ein weibliches Genital auszusehen habe, aber Greifeld bezweifelt, dass der überwiegende Teil der Malierinnen die weibliche Beschneidung als nachhaltiges Trauma einschätzt.

Ist unsere Kritik an der weiblichen Beschneidung auch aus einem neokolonialen Blick auf die «Rückständigen» gespeist - Kritik an einer Praxis, die im 19. Jahrhundert in unseren Breiten durchaus medizinisch legitimiert war? Greifeld betritt diesen Gedankengang und spricht ein zugegebenermassen schwieriges Thema an: Übertragen wir mit der Kritik an der weiblichen Beschneidung «das Orgasmus-Konzept des Globalen Nordens» auf andere Kulturen und übersehen, dass nicht nur der Körper, sondern auch Kultur die Sexualität beeinflusst, wie Foucault meinte? Gibt es in Mali Sexualitätserfahrungen, die sich vom «Globalen Norden» unterscheiden? Sind den malischen Frauen andere Themen wie Sicherheit viel zentraler und Beschneidung bedeutet für sie «Sauberkeit und Selbstkontrolle, sowie auch Schönheit und soziales «Richtigsein»» auf der Basis ihres Verständnisses von Intimität?

Was mich an Greifelds herausforderndem Ansatz beschäftigt, ist das Grundsätzliche: Emotionen regen an, aber sie können auch differenziertes Denken behindern. Mir kommen hier immer die tierschützerischen Bilder von Seehundbabys in den Sinn. Um zu sehen, dass alles nicht so einfach ist, helfen Fragezeichen meines Erachtens mehr als Ausrufezeichen. Verstehen heisst nicht legitimieren. Reflektiertes Verstehen heisst nicht zu verharmlosen, sondern besser einschätzen zu können. Wenn man etwas differenzierter einschätzen kann, wird gegebenenfalls auch die Kritik umgrenzter und präziser, reflektierter und vorsichtiger. Das betrifft in seiner allgemeinen Bedeutung übrigens nicht nur das «ferne» Afrika. Ein gerade aktuelles Beispiel: Nur wer die Argumente von Impfgegnern und Impfskeptikern sorgsam untersucht, kann auf sie auch angemessen reagieren. Eine Ethnologie der eigenen Kultur kann versuchen, Hilfestellung beim «Verstehen» zu bieten. Dann ist der Weg auch klarer zur nächsten, noch essentielleren Frage: Wo liegt die Schmerzgrenze für das kulturelle «Verstehen»? Spätestens seit der Shoa sind uns diese Grenzen klar. Aber wir sollten nicht mit dem Ende beginnen.

Eberhard Wolff*

1 Greifeld K (Hrsg.). Medizinethnologie. Eine Einführung. Berlin: Reimer; 2013 